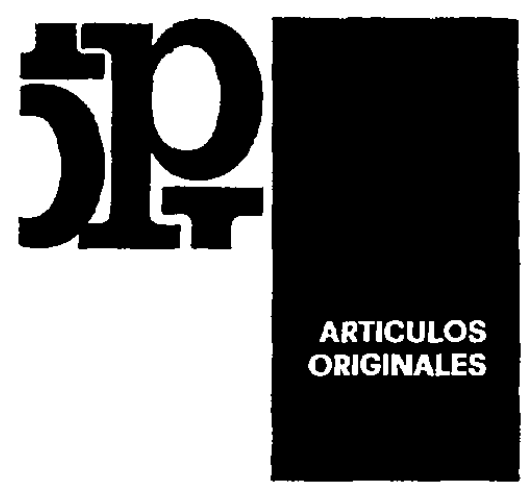

\title{
Septicemia por Salmonella Bareilly
}

\author{
DRES. G. WALTER LEDERMANN**, EDUARDO DONOSO *, MONICA CORDOYA*.
}

Quizás si la creciente integración entre clíni$\cos$ y bacteriólogos en materia de enfermedades infecciosas, sea responsable en gran parte, a través de un diagnóstico etiológico más acertado, de la frecuente declaración de casos de salmonellosis ajenas al grupo tífico tradicional. Es de todos conocida la gran frecuencia de infecciones por $\mathrm{S}$. typhimurium, ya sea como causante de diarreas o de septicemias (1) (2). Igualmente, S. newington ha tenido gran incremento en los últimos años (3) (4) y se creería que es la segunda frecuencia como causante de septicemias. Por ello resulta sorprendente, al revisar nuestro cuadro de hemocultivos de los últimos tres años, comprobar que, descontando a las typhi-paratyphi y typhimurium, la Salmonella más frecuentemente aislada de hemocultivos no es la S. newington, sino la S. bareilly. En efecto, entre 1972 y 1974 hemos tenido ocho septicemias comprobadas por este serotipo, contra dos por S. stanley y casos aislados de otros tipos (S. london, S. newington, S. eastbourne, S. enteritidis). Es cierto que, clínicamente, hemos podido sospechar septicemia en muchos de los 66 casos de diarrea por $S$. newington, acumulados en este período, pero ella no ha sido confirmada por la bacteriología. Como quiera que sea, nos ha parecido que el número relativamente importante de S. bareilly (es, además, la 4 : en frecuencia absoluta de aislamientos de Salmonella en nuestro Hospital, con 26 cepas en tres años) justificaba una revisión, a fin de determinar si todos estos casos se ajustaban a un padrón común, que permitiera orientar el diagnóstico clínico.

Salmonella bareilly es un serotipo de hallazgo frecuente, habiéndose encontrado entre nosutros con cierta regularidad en los últimos treinta años, apareciendo citada como agente de infecciones enterales por primera vez en 1945 (5). Como en

\footnotetext{
* Laboratorio Bacteriología, Hospital Calvo Mackenna.

* Servicio Infecciosos, Hospital Calvo Mackenna; e Inst. Bacterio. Iogico.
}

Chile tenemos mucha salmonellosis pero comparativamente pocas publicaciones sobre el tema, no aparece de nuevo citada hasta 1973, como contaminante de aguas (6). Revisando los archivos de la Sección Cepario (7) del Instituto Bacteriológico, que actúa como Centro Nacional de Referencia en Salmonella, se comprueba que fue de hallazgo habitual entre 1952 y 1962 , eclipsándose luego hasta 1972, año en que aparecieron los primeros casos que motivaron esta revisión. Un dato importante es que las cepas de S. bareilly identificadas en ese centro no sólo provenían de muestras humanas, sino también de alimentos, pero ninguna de animales domésticos, aun cuando en el extranjero ha sido descrita en gatos (8) .

Esta Salmonella pertenece al grupo $\mathrm{C}$ del esquema serológico de Kauffmann, que se caracteriza por el antígeno somático “ 6,7 ”. Es un serogrupo bastante conflictivo en cuanto a diagnóstico diferencial de sus constituyentes, porque la configuración antigénica flagelar de éstos es muy similar, y una misma cepa suele ser identificada de manera diferente por laboratorios que hayan empleado antisueros de distinta procedencia. La constitución antigénica completa de $\mathrm{S}$. bareilly es " 6,7 y 1,5 " y entre aquéllas con las que más se confunde, en nuestro medio, podemos citar $\mathrm{S}$. thompson y S. paratyphi C (hirschfeldii).

Un carácter distintivo, sin embargo, favorece la agrupación de nuestras cepas y es que todas ellas son incapaces de utilizar el citrato de sodio como única fuente de carbono (test de Simmons).

Los hechos más significativos de nuestra pequeña casuística se resumen a continuación, revelándonos que no existe prácticamente un padrón típico que caracterice a esta Salmonellosis. Quizás si su carácter distintivo sea su mismo polimorfismo, que se traduce en la variedad de las distintas localizaciones, entre las que la intestinal pareciera ser la excepción. 
T A B L A Nọ 1

IROBABLES (**) LOCALIZACIONES EN 8 CASOS SALMONELLOSIS BAREILLY

\begin{tabular}{lc}
\hline Loculizaciones & No de casos (*) $^{\circ}$ \\
\hline Pulmonar & $4 .-$ \\
Hepática & $3 .-$ \\
Urinaria & $3 .-$ \\
Articular & $1 .-$ \\
Intestinal & $1 .-$ \\
\hline
\end{tabular}

(**) No se demostraron bacteriológicamente.

(*) En tres casos hubo más de una localización.

De las localizaciones pulmonares, sólo en un caso hubo signos clínicos y radiológicos de fleuroneumonia, sin que se haya efectuado punción pleural o pulmonar que permitiera establecer con certeza el diagnóstico etiológico. En otras tres septicemias hubo escasos signos clínicos de compromiso pulmonar y, en las dos en que se hizo radiografía, ésta acusó neumonitis. Cabe hacer presente que en estos tres últimos casos no hubo otro foco demostrable y que los hemocultivos se tomaron cuando el cuadro pulmonar iba en regresión; por la misma tardanza en solicitarlos y por la demora propia de estos exámenes, las posibles neumopatías fueron tratadas con penicilina sódica o ampicilina. Es probable que se tratara de cuadros virales intercurrentes o por bacterias sensibles a penicilina, pero la similitud de una signología pulmonar vaga y fugaz, y la ausencia de cualquiera otra localización evidente, tientan a relacionar estos cuadros con la $S$. bareilly y a suponer que ellos evolucionaron espontáneamente, sin tratamiento específico. No hemos incluído entre las localizaciones pulmonares a un lactante de 6 meses que ingresó por bronconeumonia franca, aparecida en el curso de una diarrea prolongada, y que mejoró clínica y radiológicamente con penicilina, porque en él, el cuadro séptico, con fiebre y hepatoesplenomegalia, apareció con clara posteridad a la mejoría pulmonar. En este niño hubo 2 cuadros clínicos bien delimitados en el tiempo: una bronconeumonia sensible a penicilina y una sepsis intrahospitalaria posterior, que no creemos nos permitan buscar la unidad etiológica.

Las localizaciones hepáticas fueron más concluyentes. Si bien en un caso hubo sólo alteración de las pruebas de laboratorio, en los otros dos hubo hepatitis clínica y coma hepático, respectivamente, casos inclúdos en la reciente publicación de Zacarías y Brink (9). Los cinco niños restantes presentaron hepatomegalia, pero como no tuvieron signos clínicos de hepatitis, no se les hizo estudio funcional.
La localización articular, una artritis piógena de cadera, tampoco tuvo comprobación bacteriológica y la Salmonella se obtuvo del hemocultivo tomado al ingreso. Como su informe fue posterior al alta, el tratamiento antibiótico se planteó para germen desconocido, con cloxacilina y ampicilina: debemos suponer que ésta fue útil.

Mas en la duda quedan las posibles localizaciones del ârbol urinario. Un enfermo tuvo signos claros de infección urinaria en un cuadro séptico grave (coma hepático, melena y pleuroneumonia) y estando bajo tratamiento antibiótico, con urocultivo polimicrobiano. En un segundo niño, la muestra se tomó al tercer día de tratamiento con gentamicina y el cultivo fue negativo. En un tercer niño, el sedimento alterado fue un hallazgo en el momento del alta y pese al tratamiento con gentamicina: por desgracia, no concurrió cuando se le citó a estudio bacteriológico.

La presencia de melena repetida en un caso se consideró como índice de Jocalización intestinal evidente, en tanto que en los 7 niños restantes no existió alteración alguna que nos permitiera sospechar infección enteral. La gravedad de los distintos casos tampoco fue uniforme. Diferencias en la virulencia de las cepas o factores de terreno pudieron explicar que, mientras en dos casos la sepsis evolucionó hacia su curación en menos de una semana y sin tratamiento específico, en otros se mantuvo una evolución prolongada y tormentosa, con hemocultivos persistentemente positivos y localizaciones múltiples y severas. Todos los enfermos sanaron.

Existe, en cambio, cierta uniformidad en la edad. Seis niños eran lactantes entre 6 y 21 meses, y los dos restantes preescolares de 3 y 4 años. No hubo casos en niños mayores, en edad escolar. Cinco eran hombres y tres mujeres. Del estado nutritivo, no podemos afirmar que haya tenido importancia como factor favorecedor de la infección por este serotipo de Salmonella específicamente, ya que los enfermos iban desde el eutrófico al desnutrido grado II, y en nada se distinguían del promedio de nuestros pacientes hospitalarios, salvo un preescolar que registraba 5 hospitalizaciones por cuadros infecciosos y en el que más bien pudiera postularse un defecto inmunitaric.

En cuanto al laboratorio, aparte de los hemocultivos positivos, en un caso se buscó y se encontrô la Salmonella en las deposiciones, la que se erradicó con tratamiento antibiótico (controles negativos a 30,60 y 90 días de alta). Las reacciones de Widal fueron negativas, como era lógico esperar por la falta de comunidad antigénica de S. bareilly con el grupo tífico. En los dos pacientes en que se practicaron reacciones de aglutinación usando como antígeno la cepa obtenida del hemocultivo, la positividad fue de 1 por 800 y de 1 por 3.200 , respectivamente. La fórmula leuco- 
citaria, cuyas alteraciones adquieren en otras salmonellosis caracteres patognomónicos, fue tan variable que preferimos publicarla "in extenso" (Tabla N? 2).

T A B L A No 2

FORMULA LEUCOCITARIA EN 8 CASOS DE SALMONELLOSIS BAREILLY

Identidad clínica * Eos. Mielo Juy. Bac. Seg. Linf. Mono Total

$\begin{array}{lrrrrrrrr}\text { Neumonitis } & 0 & 0 & 0 & 15 & 52 & 32 & 1 & 7.300 \\ \text { Neumonitis } & 2 & 0 & 0 & 1 & 22 & 73 & 2 & 13.000 \\ \text { Hepatitis } & 0 & 0 & 2 & 20 & 40 & 33 & 5 & 8.300 \\ \text { Inf. urinaria } & 0 & 0 & 0 & 33 & 35 & 25 & 7 & 16.300 \\ \begin{array}{l}\text { Artritis } \\ \text { Coma hepático y }\end{array} & 0 & 0 & 0 & 29 & 52 & 15 & 4 & 7.900 \\ \text { pleuroneumonia } & 1 & 0 & 0 & 10 & 56 & 30 & 1 & 19.200 \\ \text { Neumonitis } & 0 & 1 & 0 & 5 & 10 & 82 & 2 & 4.700 \\ \text { Sin localización } & 1 & 0 & 0 & 3 & 19 & 68 & 9 & 9.800 \\ & & & & & & & & \end{array}$

* Los casos clínicos se identificaron por su principal signología.

En cuatro enfermos las cifras de leucocitos estaban dentro de límites normales y en cuatro había leucocitosis no superiores a 20.000 , con desviación izquierda en general moderada, eosinófilos normales o ausentes $y$, en dos casos, linfocitosis de $68-82 \%$. Las plaquetas siempre normales. Se encontró anemia obviamente en el caso que presentó melenas a repetición y en otro en que se sospechó sangramiento oculto, con test de Weber persistentemente negativo; también hubo cifras bajas de glóbulos rojos y hemoglobina en los niños más desnutridos. La velocidad de sedimentación fue igualmente variable, entre 20 y $100 \mathrm{~mm}$ en 1 hora.

Finalmente, un punto muy importante a considerar es la sensibilidad antibiótica, que se reseña en el cuadro siguiente (Tabla $N$ ? 3 ). Este estudio se efectuó con posterioridad a la hospitalización, de manera que no tuvo influencia en los tratamientos. La excepción la constituyó el segundo caso que tuvimos en el Servicio de Infecciosos, en que fue preciso hacer estudio de C. I. M. al fracasar el tratamiento con cloramfenicol. Como encontramos resistencia in vitro a este antibiótico y buena sensibilidad a gentamicina, tratamos con una lógica errada - todos los casos siguientes que se nos presentaron con gentamicina de partida, sin determinar previamente si las cepas eran o no sensibles a cloramfenicol o a ampicilina, an-
T A B L A No 3

SENSIBILDAD DES. BAREILLY A 4 ANTIBIOTICOS $Y$ QUIMIOTERAPICOS

$(6$ Cepas) *

\begin{tabular}{|c|c|c|}
\hline Antibiótico & Cepas sensibles & $\begin{array}{l}\text { Concentración inhibi- } \\
\text { toria minima en mi- } \\
\text { crosramos por } \mathrm{ml} \text {. }\end{array}$ \\
\hline Ampicilina & $6(100 \%)$ & $<0,2-0,78$ \\
\hline Cloramfenicol & $5(83 \%)$ & $1,56-6,25$ \\
\hline Gentamicina & $6(100 \%)$ & $0,78-3,12$ \\
\hline $\begin{array}{l}\text { Sulfametoxazol- } \\
\text { trimetoprim } \\
(20: 1)\end{array}$ & $6(100 \%)$ & $0,78-1,56$ \\
\hline
\end{tabular}

tibióticos que se mostraron útiles en tres niños tratados en otros Servicios. Por lo demás, al menos en tres enfermos hubo remisión espontánea: fueron niños en que el resultado del hemocultivo se conoció en el momento inmediatamente después del alta.

En conclusión, podemos decir que los ocho casos de septicemia por el serotipo S. bareilly acumulados en los últimos tres años, se han presentado en lactantes y pre-escolares, caracterizándose por su polimorfismo, con predominancia de las localizaciones extra-intestinales, y por su buena sensibilidad a los antibióticos habituales.

\section{RESUMEN}

Se hace una sintesis de los ocho casos de septicemia por Salmonella bareilly que se han presentado en los últimos tres años, destacándose la variedal de las localizaciones, entre las que la intestinal pareciera ser la excepción.

El estudio de las concentraciones inhibitorias minimas demuestra buena sensibilidad de S. bareilly a ampicilina, gentamicina, cloramfenicol $y$ sulfametoxazol-trimetoprim.

\section{SUMMARY}

A synthesis of eight cases of septicemia by Salmonella bareilly in the last three years is presented, outstanding the variety of different focus, anıongst which the enteric one secms to be the exception. The C.I.M.'s studies show a good sensitivity of S. bareilly to ampicillin, gentamicin, cloranphenicol and sulfametoxazo-trimethoprim. 


\section{REFERENCIAS}

1.-Prado, V; Donoso E. y Zilleruelo, G. Infección enteral por $S$. typrimurium en lactantes y sensibilidad in vitro de este germen a 7 antibióticos. Rev. Chilena Pediatría, 42: 91, 1971.

2.-Goldemberg, A.; Macaya, G, y cols. Análisis clinico de 100 niños con coprocultivo positivo a $S$. typhimurium. Bol. Inst. Bacteriológico, 15: 52, 1973.

3.-Guerrero, J. y Cassorla, R. Salmonellosis por Salmonella newington. Rev. Chilena Pediatría, 44: 129, 1973.

4.-Prenzel, I. Salmonella en localizaciones intra y extra intestinales. Bol. Inst. Bacteriológico, 15: 41, 9.-Zacarías, J. y Brink, P. Hepatitis por Salmonella. 1973.
5.-Garcés, C. Infecciones entéricas del lactante Rev. Chilena Pediatría, 16: 625, 1945.

6.- Castillo, G. y Cordano, A. M. Contaminación por Enterobacteriaceae del río Mapocho y canal Las Mercedes. Bol. Inst. Bacteriológico, 15: 40, 1973.

7.-Ledermann. G. W.; Jacob, M. y Vargas, L. Serotipos de Salmonella identificadas en el Inst. Bacteriológico de Chile desde 1952. Bol. Inst. Bacteriol6gico, vol. 16 (en prensa).

8.-Watt, J. and De Capito, Th. The frecuency and distribution of Salmonella types isolated from man and animals in Hidalgo County, Texas. Amer. Jour of Hyg., 51: 543, 1950.

Rev. Chilena Pediatría, 45: 35, 1974. 